\title{
Direct Pulp Cap
}

National Cancer Institute

\section{Source}

National Cancer Institute. Direct Pulp Cap. NCI Thesaurus. Code C52574.

The procedure in which the exposed pulp is covered with a dressing that protects the pulp and promotes healing and repair. 